\title{
The Impact on Student Learning of Resubmission of Work and Flexible Deadlines
}

\author{
Kevin M. Nickels, Mahbub Uddin \\ Department of Engineering Science \\ Trinity University
}

\begin{abstract}
Two policy initiatives were considered in this study. The first allows students to rework and resubmit previously evaluated work for additional credit. The second allows students to have a small pool of "bonus days," or declared but nonjustified extensions to homework or laboratory report deadlines. Both policies are intended to address perceived shortcomings in the traditional methods for setting deadlines and evaluating and returning student work to the student.

Student surveys indicate broad acceptance of the policies, some perception of reduced stress due to inflexible deadlines, small if any reduction in the amount of learning in the first iteration of student work, and an increased amount of attention to the homework in total.
\end{abstract}

\section{Introduction}

As educators, we are constantly looking for opportunities to maximize students' learning by continuously revising our teaching methods ${ }^{1,2}$. Two characteristics of students' homework assignments include assessment and feedback to close the gap between teaching and learning. However, assessment must be designed to broaden the learning opportunities and motivation for self-learning.

Traditionally, students are given homework with firm deadlines. The faculty member returns the graded homework with grades and feedback to students in a timely manner. To get the maximal impact from homework, students should at a minimum review the careful and thoughtful suggestions and corrections that their instructor has placed on the homework ${ }^{3,4}$. Many students, however, after a glance at the grade on the homework, file it away until the time comes for the exam review. Several obvious problems result from this behavior. First, the student does not benefit from the feedback on any coursework done between the time of the homework and the next exam. Any conceptual misunderstandings present in the work may become rooted by the time the review is done. Students cannot ask questions about instructor comments in a timely fashion. Perhaps most detrimental to student learning, students do not get practice at solving the problems in the correct fashion. By giving students incentives to review and revise homework

Proceedings of the 2003 ASEE Gulf-Southwest Annual Conference

The University of Texas at Arlington

Copyright (C) 2003, American Society for Engineering Education 
along with a relatively short time-frame in which to do these revisions, many of these problems can be mitigated.

The second problem that we attempt to address is a common one, and is becoming more common as students are becoming involved in more and more extracurricular activities. Even though instructors attempt to spread their assignments and particularly exams and projects throughout the semester, students consistently report a non-uniform distribution of work throughout the semester. If a course is not itself at a topic boundary, as indicated by an exam or major project or paper, a slight delay in coursework for that course is probably not detrimental. However, in some cases the student can see significant benefits to delaying routine reporting or problem sets by as little as one class period. Consistently giving exceptions to deadlines when asked, however, is easily abused and can even be viewed as capricious since it requires the students to attempt to justify their rationale for requesting and exception. If each student is given a small fixed number of exemptions a-priori, however, the administration of deadline extensions is greatly simplified and conducted fairly.

To address these problems, the authors in the Department of Engineering Science at Trinity University adopted a Late and Regraded Homework Policy for several engineering courses. The policy and the list of courses are outlined in Figure 1 and Table 1 respectively.

The policies listed in Figure 1 have possible pedagogic benefits. The regrade policy addresses a common desire of instructors to have students revisit past work to learn from our corrections and from their past mistakes ${ }^{5}$. There may also be indirect benefits by increasing the efficacy of coursework subsequent to the revised coursework. The regrade policy may have an additional scheduling benefit, allowing students to defer more difficult problems till they have had more time to discuss them with the instructor or with peers. The late days policy allows students greater flexibility during the sporadic periods of high activity that inevitably occur during the semester. It may also decrease pressure when students are working on an assignment for the first time, allowing them to concentrate on the content more than the scheduling.

To evaluate the inpact of these new policies, we received feedback from students at the end of each course for three consecutive semesters. In this paper, we present the result of students' perceptions with respect to the new policies, analyze the students' feedback, and evaluate the impact on students' learning. We believe "a fundamental tenet of modern learning theory is that different kinds of learning goals require different approaches to instruction; new goals for education require changes in opportunities to learn." 6

Proceedings of the 2003 ASEE Gulf-Southwest Annual Conference

The University of Texas at Arlington

Copyright (O) 2003, American Society for Engineering Education 


\section{Late and Regraded Homework Policy}

Policy

1. You will be allowed 2 late days for assigned homework. For the purpose of this policy, a day is defined to be any day on which class meets. For example, both a homework turned in on Monday that was due on Friday and a homework turned in on Wednesday that was due on Monday would be one day late.

2. After the first 2 late days, you will lose $10 \%$ (one letter grade) of the credit on an assignment for each day late, up to maximum penalty of $50 \%$. You have until one week before an exam to turn in all relevant homework, or no credit will be given.

3. You may re-submit homeworks for regrades. You may earn back up to $80 \%$ of the points originally marked off. These homeworks may be turned in with corrections by the next class period after they are handed back to you. As you need homework to study, this option is not available within one week of an exam.

\section{Rationale}

The purpose of the late days is to allow you to adjust some course deadlines according to your busy schedule. If you have a very busy week, and this course has a homework that week, you may push it off till the following week. If you get sick one week, you can make it up the next. Also, if you are studying in the core room at 2:00am the day before the homework is due and get stuck, you have the opportunity to consult with the instructor before completing the homework.

Planning is essential if you are to achieve maximal utility from these late days. Not all homeworks are equally difficult: if you spend both late days on the first homework, you won't get as much benefit as if you wait and use them when you have 4 engineering exams in a week later in the semester. They are yours to use as you wish.

The purpose of homework is to have you thoughtfully attempt all problems. If there is a misconception or computation error in a problem, you can spend lots of time trying to correct it, without learning much in the process. By allowing regrades, you have the opportunity to have instructor feedback on the homework, then look over the problems again. This opportunity to learn from your mistakes is the primary purpose for the regrade policy, and it also gives you some pre-exam feedback on how you are doing with respect to the material.

Figure 1: Late and Regraded Homework Policy

Proceedings of the 2003 ASEE Gulf-Southwest Annual Conference

The University of Texas at Arlington

Copyright (O) 2003, American Society for Engineering Education 
Table 1: Courses Surveyed

\begin{tabular}{|l|l|l|l|l|}
\hline Course & $\begin{array}{l}\text { Course } \\
\text { Level }\end{array}$ & $\begin{array}{l}\text { Required } \\
\text { Course? }\end{array}$ & $\begin{array}{l}\text { Term } \\
\text { Surveyed }\end{array}$ & $\begin{array}{l}\text { Number of } \\
\text { Responses }\end{array}$ \\
\hline Engr 2311 - Mass \& Energy Balances & Sophomore & Required & Spring 1999 & 26 \\
\hline Engr 2320 - Network Analysis & Sophomore & Required & Fall 1999 & 24 \\
\hline Engr 3327 - Thermodynamics I & Junior & Required & Fall 1999 & 38 \\
\hline Engr 4341 - Engineering Materials & Senior & Required & Fall 1999 & 17 \\
\hline Engr 4365 - Digital Logic Design & Senior & Elective & Fall 2000 & 13 \\
\hline Engr 4369 - Microcomputer Systems & Senior & Elective & Spring 1999 & 9 \\
\hline
\end{tabular}

\section{Assessment}

We tested some of these hypothesized benefits by surveying the students at the end of each course in which these policies were in force. The results encompass two years of courses taught by the authors, ranging from a required sophomore level circuit analysis course to a junior/senior level elective course in microcomputer system design.

The anonymous surveys shown in Figure 2 were completed in conjunction with course evaluations at the end of each term, before grades were computed or returned. Except where indicated, answers range from 1(Strongly Disagree) to 5 (Strongly Agree). Note that some questions are worded so that a positive response corresponds to the hypothesis and others are worded so that a negative response corresponds to the hypothesis.

\section{Late Days Questions:}

Q1) Of the 2 late days allowed for homework assignments, how many did you use? (0/1/2)

Q2) The regrade policy affected my decision as to which homeworks to turn in late.

Q3) I planned, in advance of problems actually working on the homework, which assignments to turn in late. (For example, during a week with multiple tests.)

Q4) The late policy allowed me to spend more time on the homework than I would have otherwise.

Q5) The late policy allowed me to learn more from the homework than I would have otherwise.

Q6) The reason I used the late days was: (a) Conflict with other major homework (b) Conflict with Exam (c) Sick (d) Fight with Girlfriend/Boyfriend (e) Late night partying (f) Other

Regrades Questions:

Q1) How many homeworks this semester did you re-submit for regrading? (Blank)

Q2) The regrade policy decreased how much time I spent on the homeworks initially

Q3) The regrade policy decreased how much time I spent on the homeworks in total

Q4) The regrade policy decreased the amount I learned while doing the homework the first time.

Q5) The regrade policy increased the amount I learned from the homework overall.

Figure 2: Survey Questions

Proceedings of the 2003 ASEE Gulf-Southwest Annual Conference

The University of Texas at Arlington

Copyright (C) 2003, American Society for Engineering Education 


\section{Results - Regrading Policy}

The regrading policy was somewhat less used than expected, with an average of 2.24 regraded homeworks (of between 8 and 13 total assignments). This was one of the few aspects where the authors' students differed, with Dr. Uddin's students averaging 2.77 assignments and Dr.

Nickels' students averaging 1.36 assignments. The reasons for this seem to be related to the course type, as Dr. Nickels' elective courses in Digital Logic Design and Microcomputer Design standing out as low-utilization outliers ( 0.5 and 0.89 assignments per student respectively). With regard to student learning from the homework, the students felt that the availability of regrades did not lead them to spend less time on the homework, either on the first pass (1.81) or in total (1.90). The students did believe (3.59) that the policy increased the amount learned from the homework in total. The numerical data are presented below in Figure 3 through Figure 7.

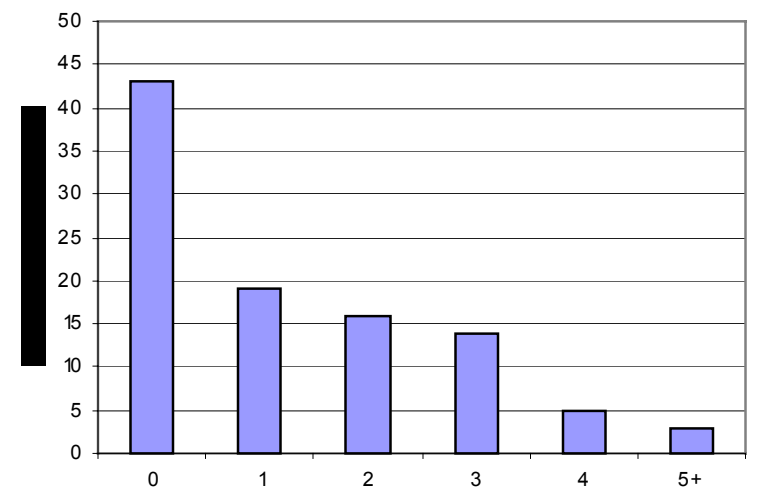

Figure 3: How many homeworks this semester did you re-submit for regrading?

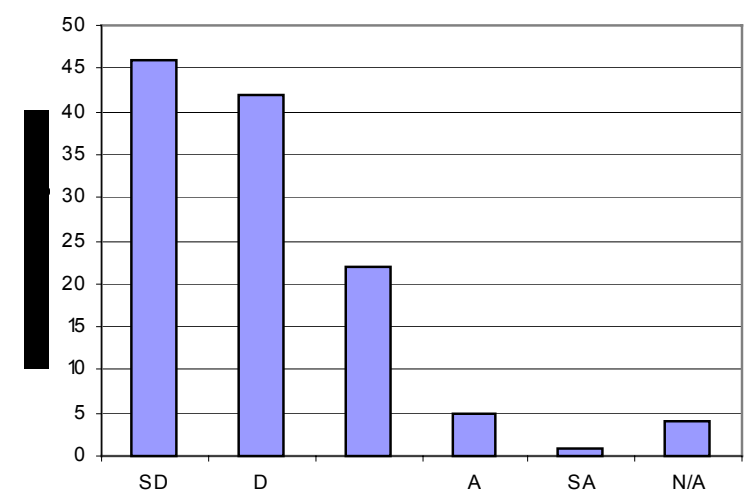

Figure 5: The regrade policy decreased how much time I spent on the homeworks in total

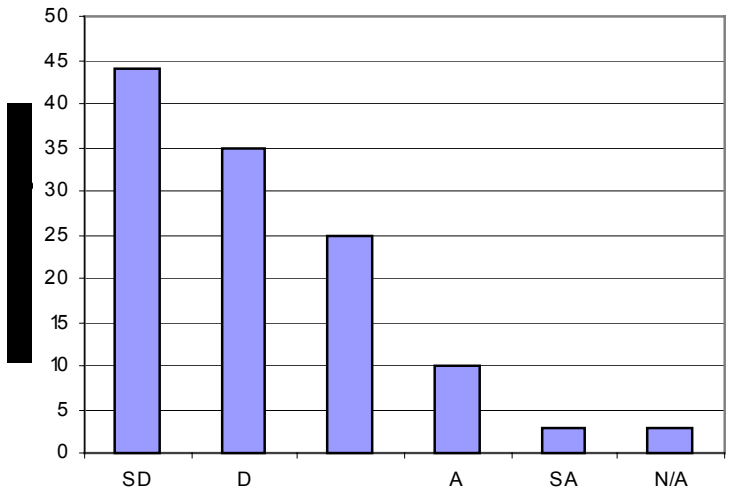

Figure 4: The regrade policy decreased how much time I spent on the homeworks initially

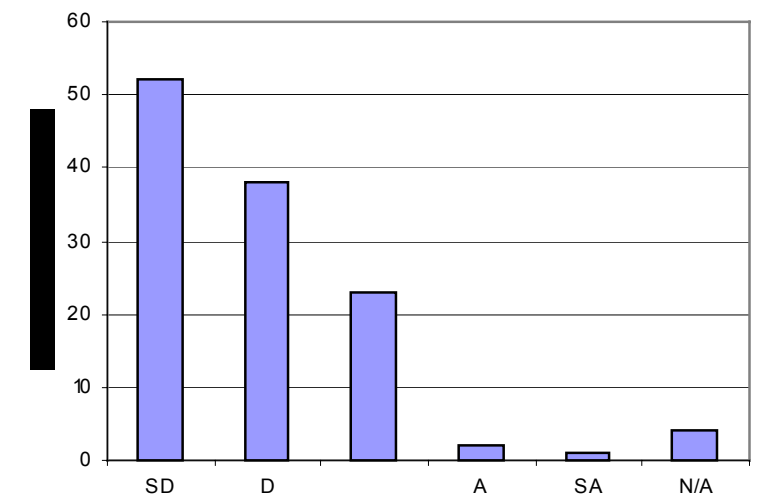

Figure 6: The regrade policy decreased the amount I learned while doing the homework the first time. 


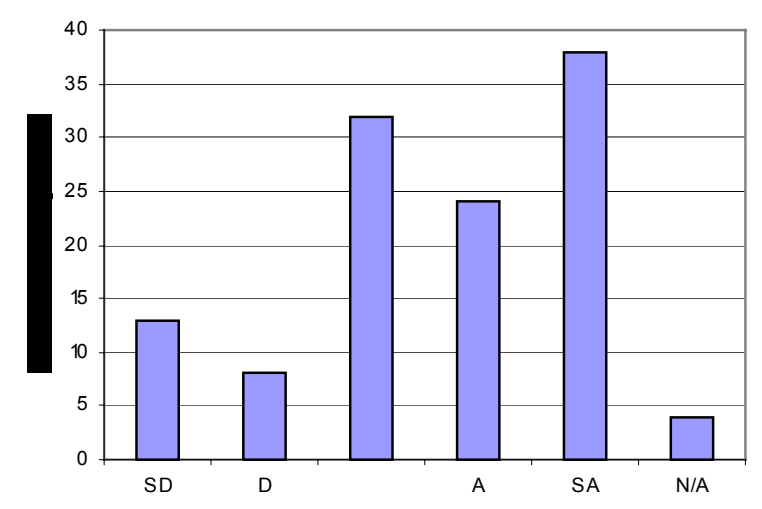

Figure 7: The regrade policy increased the amount I learned from the homework overall

There were several student comments to back up these analyses. With regard to the low utilization of regrades, several students commented that the one-week suspension of the policy before exams was problematic. Others felt that there was not enough incentive $(80 \%$ of the points lost) when the original scores were high or, similarly, that reworking the errors involved too much work.

- It seemed like all the homework assignments that I need a regrade on I couldn't get because of testing.

- I never really used the regrade policy. It took enough time to do it the first time and could not spend more time regrading [reworking the problems?]

- Late days and option to regrade good, though I would rather spend hours on the first time and get it right as I can rather than go back. In this class it is my opinion that it would be too hard and time consuming to redo homework b/c [because] after we turn in one assignment, we have a new one to start.

- If I had done very poorly on any of the homeworks, I would have taken advantage of the regrade policy. However, reworking the homework for maybe a few points was not worth the time.

- As the semester went on and the homework got harder and other homework increased, the time available to re-submit homeworks decreased.

- I never used regrades because I was already too busy playing catch-up to begin with.

- Didn't use regrades, b/c [because] homeworks were only about 20 pts/assignment. Most of them were high- $80 \%$ return might have meant a point or two.

Unexpectedly, some students took the regrade policy as an opportunity to submit a draft of the homework originally, and then really concentrate on the second submission, treating the regrade policy as a modified time-shifting policy.

Proceedings of the 2003 ASEE Gulf-Southwest Annual Conference

The University of Texas at Arlington

Copyright (C) 2003, American Society for Engineering Education 
- It was very helpful to have a second chance to do homework, especially since there were many conflicts with exams. It gave us the opportunity to learn the material, even if it was a few days late.

Overall, the students felt that the regrade policy did result in increased learning from the homework.

- I really liked the regrade policy because I felt like I had a much better overall understanding of the material when I reviewed it a second time.

- The regrade policy provides incentive to look over old homework assignments and correct them when otherwise they would have just been buried in my other notes without a second look.

- Regrading was very useful, it did not have a huge affect on how I did the homework the first time, but it did cause me to go back and learn from my mistakes, which I most likely would not have bothered to do otherwise.

- It is a good way of giving us a second chance to learn the material and get the skills necessary to ace a test.

- Even though I didn't use the regrade possibility it was nice to know that I had the option, and it allowed me to be a little more relaxed while doing the homework.

- The regrade policy helped me to take a fresh approach to some problems and discuss with prof [professor]

\section{Results - Late Days}

The late days policy showed a relatively high usage of 1.43 late days out of the allowed 2 possible days. The students showed ambivalence (2.98) on whether the possibility of regrades affected their decision as to which assignments to turn in late. Students also had no agreement on the amount of planning induced by the late days policy. That is, whether this policy caused students to plan, in advance of actually working on the homework, which assignments they would turn in late. The students did believe that they spent more time on the homework in total than they would have without the policy (4.09) and that they learned more from the homework than they would have otherwise (3.97). The reasons stated for using late days are unsurprising, with conflicts with other major homework ( $70.8 \%$ of respondents reported this as a reason for using a late day) and with exams (60.8\%) topping the list. Numerical results from the surveys are presented in Figure 8 through Figure 13.

Proceedings of the 2003 ASEE Gulf-Southwest Annual Conference

The University of Texas at Arlington

Copyright (O) 2003, American Society for Engineering Education 


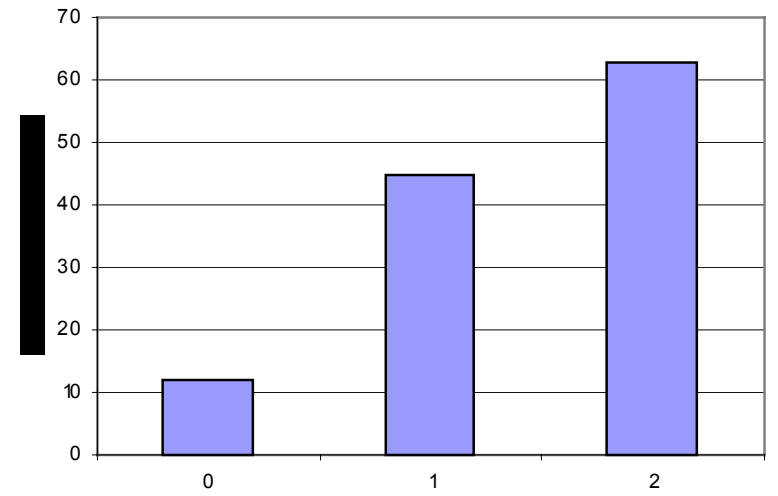

Figure 8: Number of Late Days Used

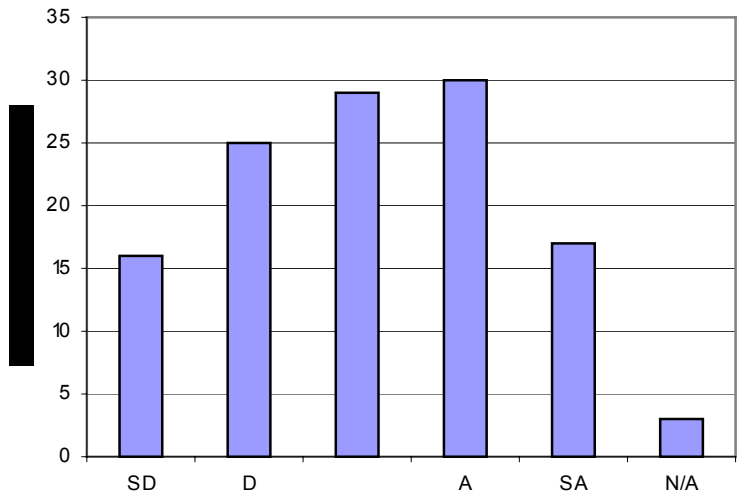

Figure 10: I planned, in advance of problems actually working on the homework, which assignments to turn in late. (For example, during a week with multiple tests.)

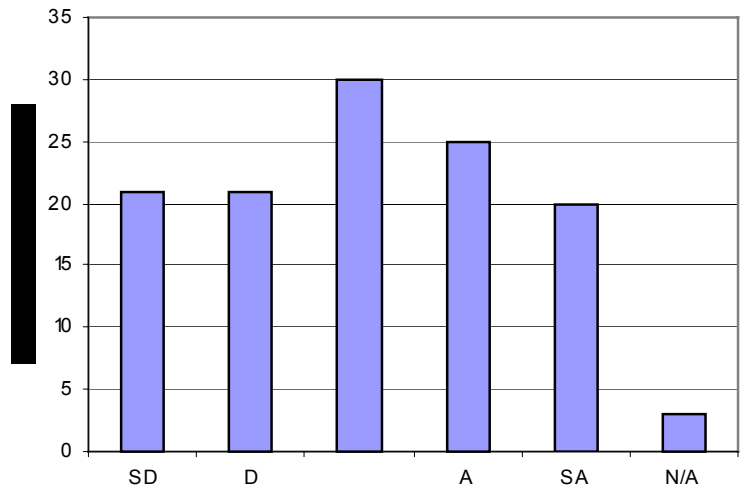

Figure 9: The regrade policy affected my decision as to which homeworks to turn in late.

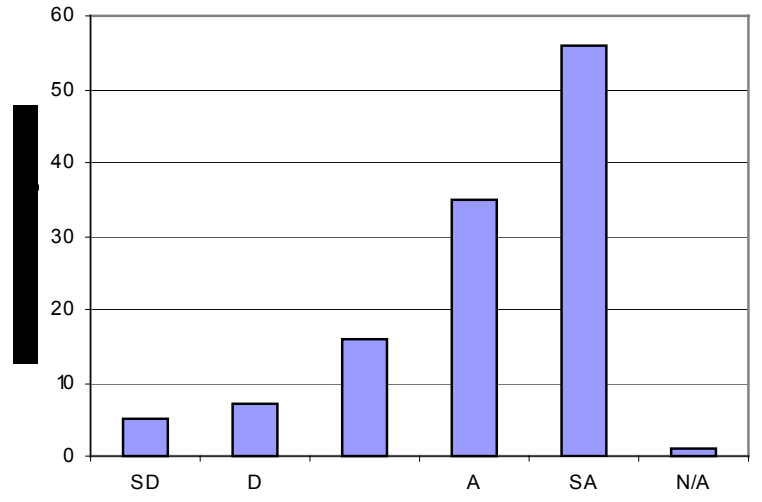

Figure 11: The late policy allowed me to spend more time on the homework than I would have otherwise. 


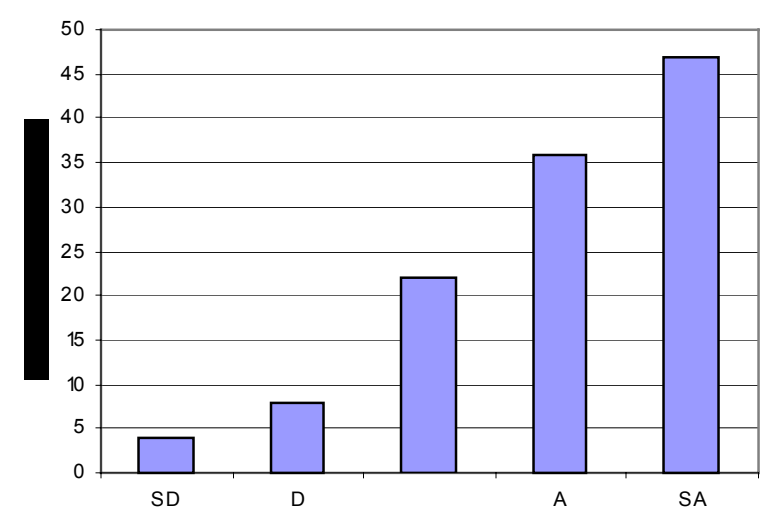

Figure 12: The late policy allowed me to learn more from the homework than I would have otherwise.

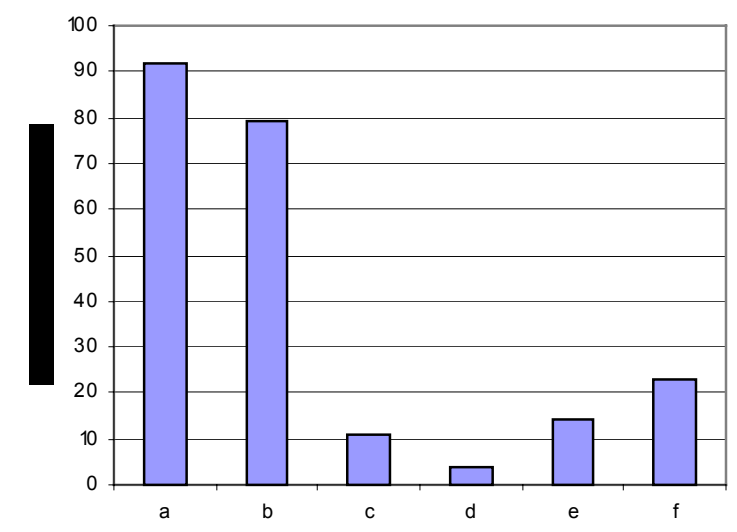

Figure 13: The reason I used the late days was: (a) Conflict with other major homework (b) Conflict with Exam (c) Sick (d) Fight with Girlfriend/Boyfriend (e) Late night partying (f) Other

Again, the free-form comments reflect many of these quantitative assessments. One common complaint about the late days pertains to the period before an exam. The problem set before an exam is not eligible for late days, so that the graded work can be returned to the students in time to study for the exam. Several students feel that this is when they most need the opportunity to turn in homework late, or didn't understand when this was the case.

- The homework that was not allowed late due to tests were the ones I needed to turn in late the most. My tests seemed to always fall around the same time. I never really used the regrade policy. It took enough time to do it the first time and could not spend more time regarding [reworking the problems?]

- Late days were real applicable for me. I do like the ability to have late days. I'd just like it spelled out more when we could use them. (Were there homeworks that we couldn't use them on?)

In addition to the expected benefit of load equalization, for some students the late days policy made the difference between not doing any homework and working on it.

- The late days policy was good because there is so much other stuff going on at school that it is good to have a little extra time.

- This policy helped dramatically at times when I was loaded down with homework.

- I think both policies allow more homework to get done. Classes w/o this policy get some homework pushed aside. Sometimes there just isn't enough time to do homework, so the late policy gives extra time. I definitely learn more when I do the homework.

- I think it is a very good policy. It makes us work harder and learn more while being a little understanding with other commitments either planned or unplanned. I really like this policy. 
- The late days are very helpful this class is very labor intensive and it is good to be able to postpone an assignment if other less tolerant classes get very busy.

\section{Analysis of Results}

Since the survey covered a wide range of courses, from introductory required courses in circuit analysis and thermodynamics to electives in microcomputer systems design, there was surprising agreement in response. The two outstanding discrepancies between instructors were in the reasons for late days (conflict with exams --- Dr. Uddin@72\%, Dr. Nickels@ 46\%) and in the aforementioned regrade usage. The regrade usage can be tracked to specific courses: digital logic design and microcomputer systems design are both junior/senior elective courses and contain a larger project-based component than the other courses surveyed. Due to this, a rework of an assignment may be viewed as more effort than in a problem-set. In addition, due to the self-selection of students in elective courses, motivation and performance on each assignment could be higher in elective courses than in required courses.

\section{Conclusions and Recommendations}

The late days policy is a popular policy that allows students to defer homework when conflicts exist with other homework and exams. Students seem to use these opportunistically, not planning in advance when to use them, but using them when too much is going on. The perception exists that the policy allows students to shift deadlines, allowing work on assignments that may not have been done otherwise, and increasing learning as a result. Since the instructor retains the ability to suspend the policy near major projects or exams, there seems to be no major pedagogic penalty for utilizing this method.

The regrade policy is also popular with students, allowing them to look over and correct errors in their assignments. Students do not believe that the availability of regrades detracted from their learning or time spent on the initial submission, but did believe that the total learning was increased.

We believe that each of these policies can increase learning as a result of homework and problem sets, if used correctly. With the limits and restrictions placed on the policies to avoid especially harmful procrastination of assignments (for example, near exams) we also believe that the policies do not significantly detract from the relevant course but do aid the students in both scheduling their work and in making better use of the feedback on assignments.

Proceedings of the 2003 ASEE Gulf-Southwest Annual Conference

The University of Texas at Arlington

Copyright (C) 2003, American Society for Engineering Education 


\section{References}

1. Finelli, C., Klinger, A., and Bundy, D. "Strategies for Improving Classroom Environment," Journal of Engineering Education, vol. 90, no. 4, October 2001, pp. 491-497.

2. Felder, R. M. "A Longitudinal Study of Engineering Student Performance and Retention IV: Instructional Methods and Student Responses to them," Journal of Engineering Education, vol. 84, no. 4, October 1995, pp. 361-367.

3. Dutson, A. J., Todd, R., Magleby, S., and Sorensen, C. "A review of literature on teaching engineering design through project-oriented capstone courses," Journal of Engineering Education, vol. 86, no. 1, January 1997, pp. $17-28$.

4. Dunn, R., and Dunn, K. Teaching Students through their individual learning styles: a practical approach. Prentice-Hall: Reston, Virginia, 1978.

5. Larkin-Hein, T. and Budny, D. D. "Research on Learning Style: Applications in the Physics and Engineering Classrooms," IEEE Transactions on Education, vol. 44, no. 3, August 2001, pp. 276-281.

6. Bransford, J. D., Brown, A. L., and Cocking, R. R. How People Learn. National Academy Press: Washington, D.C., 1999.

\section{KEVIN M. NICKELS}

Dr. Kevin M. Nickels is an assistant professor in the Department Engineering Science at Trinity University. He received the B.S. degree in Computer and Electrical Engineering from Purdue University (1993), and received the M.S. degree (1996) and the Ph. D. (1998) in Electrical Engineering from The University of Illinois at UrbanaChampaign. He is currently working in the areas of computer vision, pattern recognition, and robotics. Dr. Nickels has been a member of ASEE since 1998 and a member of IEEE since 1994.

\section{MAHBUB UDDIN}

Dr. Mahbub Uddin is a professor and the chairman of the Department of Engineering Science at Trinity University. He received a Ph.D. in Chemical Engineering in 1983 from Oklahoma State University. His research interests include stochastic approaches in process design and simulation, failure analysis of polymeric material, heat exchanger design, hydrodynamics and heat transfer characteristics of two-phase follow in helically coiled tubes, pollution control and advances in undergraduate engineering education. Dr. Uddin as an active member of AIChE and ASEE. His honors include: DOW Chemical, Outstanding Young Faculty Award, 1987; New Engineering Educators Excellence Award, ASEE, 1987; William Liston Zander Faculty Fellow Award, Trinity University, 1988; Outstanding New Engineering Educators Award, NEEE, 1989; Dr. and Mrs. Z.T. Scott Faculty Fellowship Award for Outstanding Achievement in Teaching and Advising, Trinity University, 1994; Most Outstanding Professor in the Department of Engineering Science, Mortar Board Honor Society, Trinity University, 1996, and Fellow, American Society for Engineering Education, 1998.

Proceedings of the 2003 ASEE Gulf-Southwest Annual Conference

The University of Texas at Arlington

Copyright (C) 2003, American Society for Engineering Education 